\begin{tabular}{|c|c|c|}
\hline \multirow{3}{*}{$\begin{array}{r}\text { Case Reports in } \\
\text { Gastroenterology }\end{array}$} & \multirow{2}{*}{\multicolumn{2}{|c|}{ Case Rep Gastroenterol 2015;9:68-73 }} \\
\hline & & \\
\hline & $\begin{array}{l}\text { DOI: 10.1159/000369248 } \\
\text { Publisned ontine: IViarch 14, } 2015\end{array}$ & $\begin{array}{l}\text { (c) } 2015 \text { S. Karger AG, Basel } \\
1662-0631 / 15 / 0091-0068 \$ 39.50 / 0 \\
\text { www.karger.com/crg }\end{array}$ \\
\hline & \multicolumn{2}{|c|}{$\begin{array}{l}\text { This is an Open Access article licensed under the terms of the Creative Common } \\
\text { Attribution-NonCommercial } 3.0 \text { Unported license (CC BY-NC) (www.karger.com/OA } \\
\text { license), applicable to the online version of the article only. Distribution permitted for non } \\
\text { commercial purposes only. }\end{array}$} \\
\hline
\end{tabular}

\title{
Spontaneous Hepaticoduodenal and Choledochoduodenal Fistula Mimicking Duodenal Ulcer Perforation, a Very Rare Complication of Transarterial Chemoembolization
}

\author{
Varayu Prachayakul ${ }^{\mathrm{a}} \quad$ Pitulak Aswakul $^{\mathrm{b}}$ \\ asiriraj Gastrointestinal Endoscopy Center, Division of Gastroenterology, Department of \\ Internal Medicine, Siriraj Hospital, Faculty of Medicine, Mahidol University, and ${ }^{b}$ Liver and \\ Digestive Institute, Samitivej Sukhumvit Hospital, Bangkok, Thailand
}

\section{Key Words}

Hepaticoduodenal fistula $\cdot$ Choledochoduodenal fistula $\cdot$ Fistula $\cdot$ Transarterial chemoembolization · Complications

\begin{abstract}
Spontaneous bilo-enteric fistula is a rare complication following surgery or some therapeutic interventions such as transarterial chemoembolization (TACE). The present case was a young man, a known case of chronic hepatitis B with multiple recurrent hepatocellular carcinoma, who presented with clinical sepsis and jaundice. Computed tomography showed dilated proximal left intrahepatic ducts which suspected anastomotic stricture. He underwent endoscopic retrograde cholangiopancreatography, but the endoscopic view showed a deep ulcer covered by yellowish debris tissue. After re-evaluation it was found to be hepaticoduodenostomy and choledochoduodenostomy tracts. In the present case the fistula was suspected to be related to a previous TACE procedure.

(C) 2015 S. Karger AG, Basel
\end{abstract}

\section{Introduction}

Hepatocellular carcinoma (HCC) is a leading liver-related cancer worldwide accounting for more than 600,000 cases every year; there is variation of the incidence of HCC with a

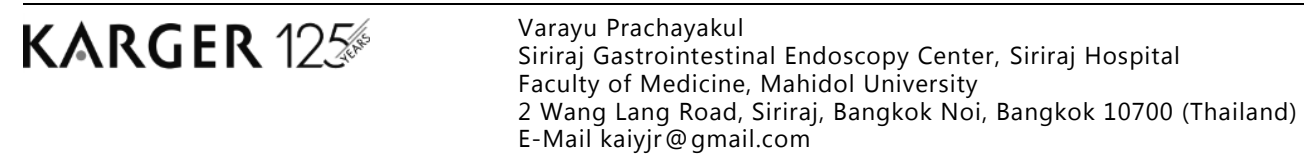


Prachayakul and Aswakul: Spontaneous Hepaticoduodenal and Choledochoduodena Fistula Mimicking Duodenal Ulcer Perforation, a Very Rare Complication of TACE

higher incidence in Eastern Asia and sub-Saharan Africa. There are many known risk factors associated with the development of HCC, such as chronic hepatitis B and C infection, cirrhosis, nonalcoholic steatohepatitis and hereditary hemochromatosis [1]. The curative treatments for HCC are surgery such as hepatectomy or liver transplantation and local ablative treatments such as radiofrequency ablation or percutaneous ethanol injection. However, unfortunately only $20-30 \%$ of patients are suitable for this treatment. In case of unresectable HCC, the alternative treatments are transarterial chemoembolization (TACE) with or without systemic chemotherapy, whereas patients with terminal-stage disease receive only supportive treatment [2]. TACE is a standard treatment for patient with unresectable HCC without systemic metastases and has been reported to prolong survival and to control the symptoms of HCC. TACE is performed by injection of anti-cancer drugs such as doxorubicin, epirubicin, cisplatin or miriplatin and iodinized oil (Lipiodol Ultra-Fluide, Laboratoires Guerber, Aulnay-sous-Bois, France) into the hepatic artery followed by the administration of the embolic agents. The most common adverse events after TACE are nausea and vomiting, post-embolization syndrome, bleeding or transient hepatic impairment $[3,4]$. The rare complications reported are duodenal perforation or hepatic abscess [5], post-embolization hepatic rupture [6], necrotizing pancreatitis [7], spinal cord injury [8], cerebral embolism [9, $10]$, tumor lysis syndrome [11] or spontaneous bilo-enteric fistula [12,13].

Here, we reported a rare case of spontaneous hepaticoduodenal and choledochoduodenal fistula following TACE. Written informed consent was obtained from the patient for publication of this case report and any accompanying images. A copy of the written consent form is available for review from the editor of this journal.

\section{Case Presentation}

The patient was a 34-year-old gentleman, a known case of chronic hepatitis B with multifocal HCC who underwent right lobe hepatectomy with cholecystectomy 4 years ago. He had recurrent HCC at segment III and caudate lobe, thus he underwent three TACE procedures followed by wide caudate lobe resection couple years before. In this episode he presented with jaundice, high-grade fever and severe abdominal pain for 3 days. His blood works showed leukocytosis with neutrophilia. Liver chemistry showed hyperbilirubinemia which total/direct bilirubin $12.9 / 11.2 \mathrm{mg} / \mathrm{dl}$ (reference $0.2-1.0 \mathrm{mg} / \mathrm{dl}$ ), aspartate transaminase and alanine transaminase were 75 and $53 \mathrm{U} / \mathrm{l}$ (reference 0-38 U/l), and alkaline phosphatase was $209 \mathrm{U} / \mathrm{l}$ (reference 39-117 U/l). Computed tomography showed a 6-mm common bile duct with mild left intrahepatic duct dilatation. Proximal left intrahepatic duct stricture was suspected; therefore, he was scheduled for endoscopic retrograde cholangiopancreatography and biliary drainage.

The patient was positioned in the left lateral decubitus position and sedated using intravenous propofol under full anesthetic monitoring. After duodenal intubation with a duodenoscope, a large duodenal ulcer was seen in the duodenal bulb, so the scope was changed to be standard gastroscope. The endoscopic view showed a $1.5-2.0-\mathrm{cm}$ duodenal ulcer covered by yellowish debris tissue. After carefully checking the ulcer, two openings were seen at the ulcer base (fig. 1) with whitish epithelial lining of the larger one, therefore a 0.035 -inch guidewire was passed through these two nonsurgical openings (fig. 2) followed by contrast injection. The authors found that one of the openings was a choledochoduodenal fistula and the other one a hepaticoduodenal fistula (fig. 3). After revision of his surgical procedures, no surgical bypass was performed at all in this particular patient. The authors hypothesized that these fistulas were spontaneously created and might be the consequence of TACE pro- 
Prachayakul and Aswakul: Spontaneous Hepaticoduodenal and Choledochoduodena Fistula Mimicking Duodenal Ulcer Perforation, a Very Rare Complication of TACE

cedures which had caused ischemia and necrosis of the liver. The obstructive jaundice was due to the obstruction of the openings by food particles and a strictured bile duct at segments II and III, so two plastic stents (10 Fr, $7 \mathrm{~cm}$ ) were inserted with good bile flow (fig. 4). The patient was followed up a month later. He was doing well and his liver chemistries were normal.

\section{Discussion}

Spontaneous bilo-enteric fistula is a very rare complications following some treatment interventions, the most common cause being surgery. There are only few case reports regarding this condition as an adverse events from severe inflammatory process such as acute pancreatitis or TACE [12-15]. The principle of TACE is tumor ischemia that occurs from blocking of the arterial blood supply of the liver tumor combined with chemotherapy administered directly into the tumor. However, the normal liver tissue and adjacent organs can be affected by unintentional proximal artery embolization that leads to uncommon complications such as duodenal perforation or acute pancreatitis. In the present case, the fistulas might not only have been caused by repetitive TACE procedures, but also by altered anatomy from repetitive liver resections. In general, the definitive treatment of fistulas is surgical correction, but in this particular case, this might not have been possible because of inflammation and fibrosis of the surrounding tissue.

Leaving the fistula tracts opened might be an appropriate treatment strategy. Nevertheless, this patient still developed acute cholangitis that was complicated by obstruction of the fistula openings by food particles and proximal segmental bile duct stricture. Therefore, the authors planned for long-term biliary stenting in this patient. Finally, highly selective TACE is essential to prevent ischemia-related complications.

\section{Author Contributions}

V. Prachayakul developed the concept. V. Prachayakul and P. Aswakul wrote and revised the paper for important intellectual content. Both authors read and approved the final manuscript.

\section{Disclosure Statement}

The authors have no conflicts of interest or financial ties to disclose.

\section{References}

1 Goh LY, Leow AH, Goh KL: Observations on the epidemiology of gastrointestinal and liver cancers in the Asia-Pacific region. J Dig Dis 2014;15:463-468.

2 Fong ZV, Tanabe KK: The clinical management of hepatocellular carcinoma in the United States, Europe, and Asia: a comprehensive and evidence-based comparison and review. Cancer 2014;120:2824-2838.

-3 Dai QS, Gu HL, Ye S, Zhang YJ, Lin XJ, Lau WY, Peng ZW, Chen MS: Transarterial chemoembolization vs. conservative treatment for unresectable infiltrating hepatocellular carcinoma: a retrospective comparative study. Mol Clin Oncol 2014;2:1047-1054. 
Prachayakul and Aswakul: Spontaneous Hepaticoduodenal and Choledochoduodenal Fistula Mimicking Duodenal Ulcer Perforation, a Very Rare Complication of TACE

-4 Cohen MJ, Bloom AI, Barak O, Klimov A, Nesher T, Shouval D, Levi I, Shibolet O: Trans-arterial chemo-embolization is safe and effective for very elderly patients with hepatocellular carcinoma. World J Gastroenterol 2013;19:2521-2528.

-5 Xia J, Ren Z, Ye S, Sharma D, Lin Z, Gan Y, Chen Y, Ge N, Ma Z, Wu Z, Fan J, Qin L, Zhou X, Tang Z, Yang B: Study of severe and rare complications of transarterial chemoembolization (TACE) for liver cancer. Eur J Radiol 2006;59:407-412.

6 Jia Z, Tian F, Jiang G: Ruptured hepatic carcinoma after transcatheter arterial chemoembolization. Curr Ther Res Clin Exp 2013;74:41-43.

7 Bae SI, Yeon JE, Lee JM, Kim JH, Lee HJ, Lee SJ, Suh SJ, Yoon EL, Kim HR, Byun KS, Seo TS: A case of necrotizing pancreatitis subsequent to transcatheter arterial chemoembolization in a patient with hepatocellular carcinoma. Clin Mol Hepatol 2012;18:321-325.

-8 Jia ZZ, Tian F, Jiang GM: Cerebral lipiodol embolism after transarterial chemoembolization for hepatic carcinoma: a case report. World J Gastroenterol 2012;18:4069-4070.

-9 Kumar R, Hassan SM, Faiq SM, Abbas Z, Luck NH: Thalamic and midbrain infarct during transarterial chemoembolization of hepatocellular carcinoma. J Pak Med Assoc 2012;62:295-297.

10 Tufail K, Araya V, Azhar A, Hertzog D, Khanmoradi K, Ortiz J: Paraparesis caused by transarterial chemoembolization: a case report. World J Hepatol 2010;2:289-291.

11 Wang K, Chen Z: Acute tumor lysis syndrome after transarterial chemoembolization for well-differentiated hepatocellular carcinoma with neuroendocrine features. Onkologie 2010;33:532-535.

12 Wang CY, Leung SW, Wang JH, Yu PC, Wang CC: Delayed spontaneous hepatogastric fistula formation following transcatheter arterial embolisation and radiotherapy for hepatocellular carcinoma. $\mathrm{Br} \mathrm{J}$ Radiol 2009;82:e105-e107.

13 Park YH, Kang SH, Kim SU, Kim do Y, Park JY, Ahn SH, Han KH, Chon CY: A case of hepaticoduodenal fistula development after transarterial chemoembolization in patient with hepatocellular carcinoma. Korean J Gastroenterol 2011;58:149-152.

14 Brandes G, Schennetten M: Spontaneous choledochoduodenostomy in gallbladder carcinoma with pancreatitis. Arztl Wochensch 1954;9:1173-1175.

15 Pua U, Merkle EM: Case report. Spontaneous cholecystocolic fistula and locoregional liver tumour ablation: a cautionary tale. Br J Radiol 2011;84:e243-e245.

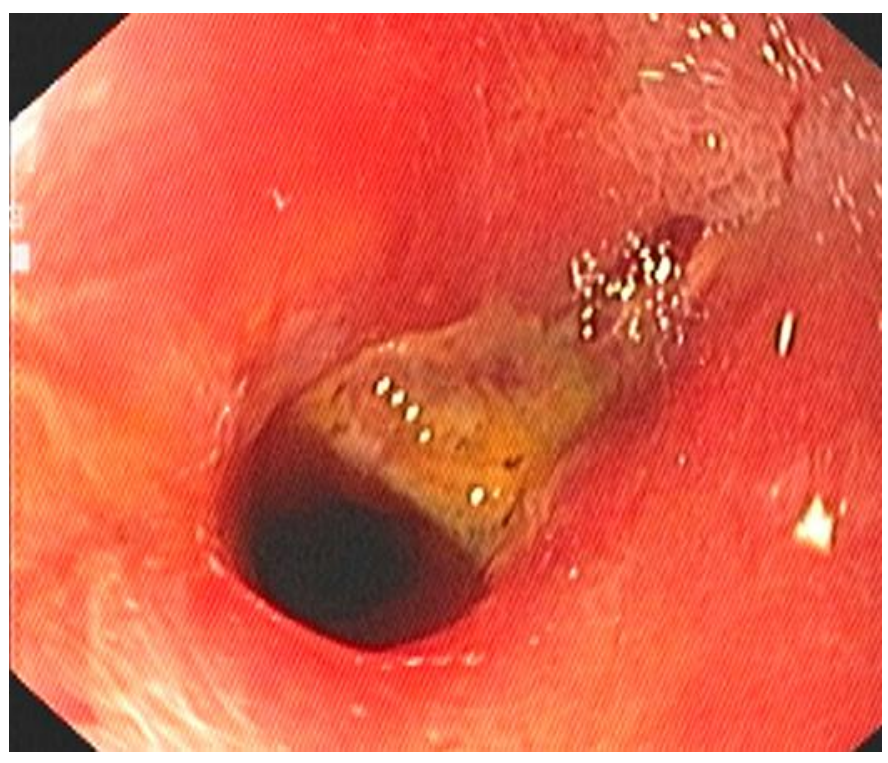

Fig. 1. A 2.0-cm duodenal ulcer covered by yellowish debris tissue with two openings at the ulcer base. 


\begin{tabular}{rl|l} 
Case Reports in & \multicolumn{2}{l}{} \\
\cline { 2 - 3 } Gastroenterology & Case Rep Gastroenterol 2015;9:68-73 & $\begin{array}{l}\text { ○ 2015 S. Karger AG, Basel } \\
\text { www.karger.com/crg }\end{array}$ \\
\cline { 2 - 3 } & DOI: 10.1159/000369248 & Prachayakul and Aswakul: Spontaneous Hepaticoduodenal and Choledochoduodenal
\end{tabular}

Fistula Mimicking Duodenal Ulcer Perforation, a Very Rare Complication of TACE

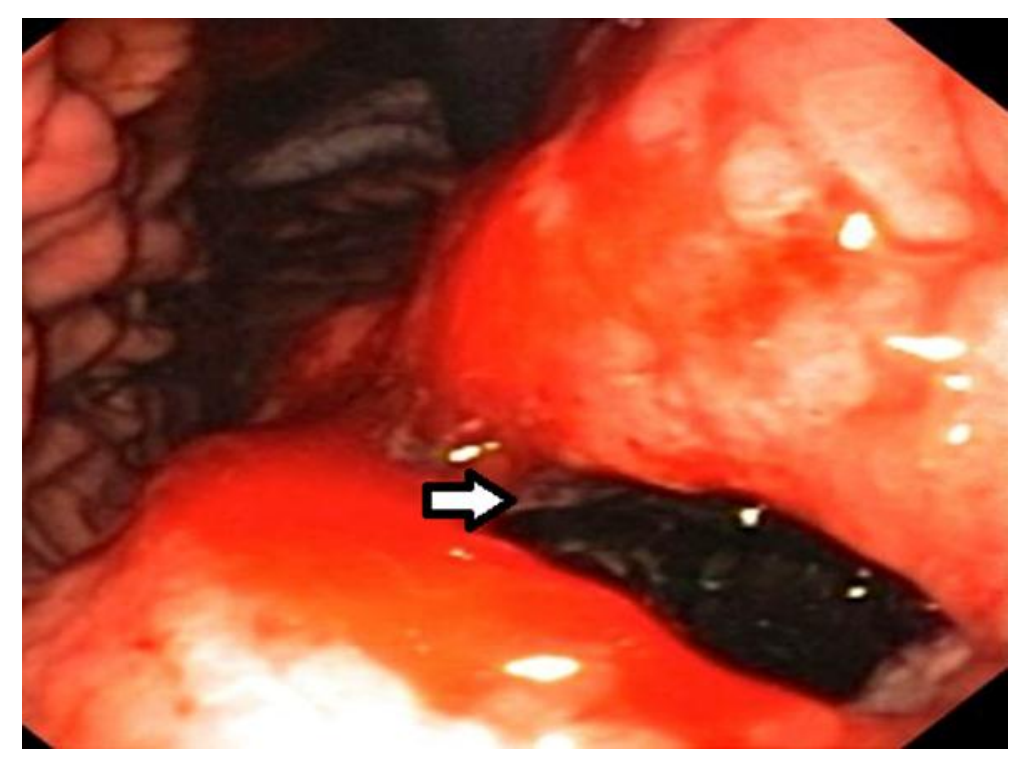

Fig. 2. The guidewire was passed through one of the two openings.

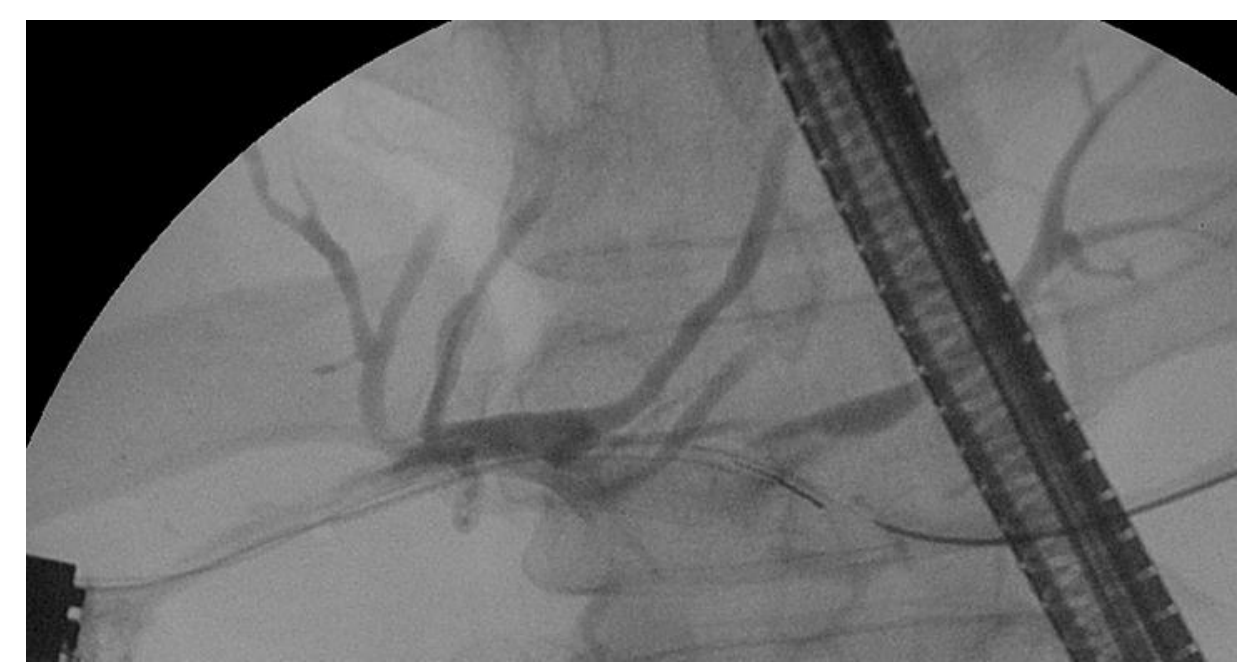

Fig. 3. One of the openings was a hepaticoduodenal fistula. 


\begin{tabular}{ll|l} 
Case Reports in & \multicolumn{2}{l}{} \\
\cline { 2 - 3 } Gastroenterology & Case Rep Gastroenterol 2015;9:68-73 & $\begin{array}{l}\text { @ 2015 S. Karger AG, Basel } \\
\text { www.karger.com/crg }\end{array}$ \\
\cline { 2 - 3 } & DOI: 10.1159/000369248 &
\end{tabular}

Prachayakul and Aswakul: Spontaneous Hepaticoduodenal and Choledochoduodenal Fistula Mimicking Duodenal Ulcer Perforation, a Very Rare Complication of TACE

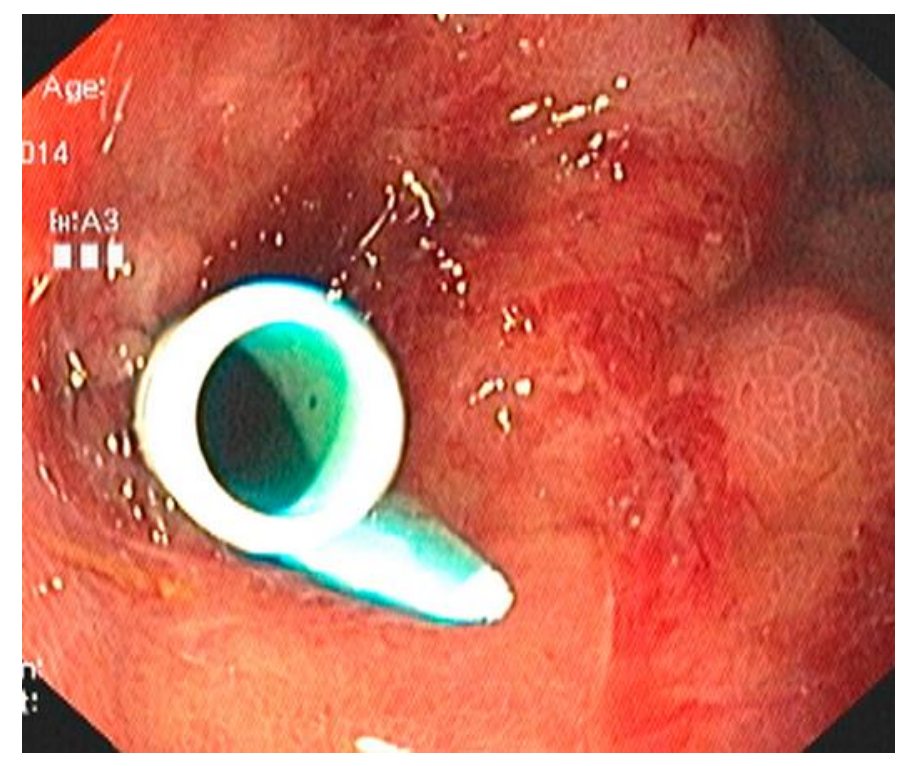

Fig. 4. A plastic stent $(10 \mathrm{Fr}, 7 \mathrm{~cm})$ was inserted into the left intrahepatic duct. 